Archived version from NCDOCKS Institutional Repository http://libres.uncg.edu/ir/asu/

\title{
Appalachỉan
}

B O O N E, N O R T H C A R O L I N A

\section{Scientific Literacy In The Wild: Using Multimodal Texts In And Out Of School}

\author{
By: Beth A. Buchholz and Damiana Gibbons Pyles
}

\begin{abstract}
Building a better public education system for our children begins with providing students with real-world learning experiences from the very beginning. To this end, the authors explored how two kindergarten teachers scaffolded scientific literacy learning using an authentic multimodal text before, during, and after a zoo field trip in ways that fostered the identity of kinder "scientists" along with good literacy skills. From their experiences, public educators can help their students develop strong science knowledge and scientific literacy through rich literacy practices intertwined with learning science content, over a period of time, with multiple, varied, and scaffolded uses of an authentic, multimodal text and paired with authentic, out-of-school learning experiences.
\end{abstract}

Buchholz, B.A., \& Pyles, D.G. (2018). Scientific Literacy in the Wild: Using Multimodal Texts In and Out of School. The Reading Teacher, 72( 1), 61-70. https://doi.org/10.1002/trtr.1678. Publisher version of record available at: https://ila.onlinelibrary.wiley.com/doi/full/10.1002/trtr.1678 


\title{
Scientific Literacy in the Wild: Using Multimodal Texts in and out of School
}

\author{
Beth A. Buchholz, Damiana Gibbons Pyles
}

\author{
Teachers integrate an authentic, multimodal informational text before, during, \\ and after a field trip to the zoo as a way of promoting real-world scientific \\ literacy with young students.
}

\begin{abstract}
The door to the aviary opens with a blast of muggy air. With their first steps into the glass building, students are alert, scanning their lush surroundings for the slightest movement or noise that hints at the possibility of spotting a bird. Clutching their well-read, well-loved aviary bird guides in one hand and crayons to record their findings in the other, these kindergartners are ready to be scientists as well as readers and writers. One student excitedly points up in the trees and then down by the creek, then describes a bird's physical characteristics. A small group of students works together to locate and circle the species on their guides before proclaiming in unison, "We just saw a golden white-eye!"
\end{abstract}

W ith mounting pressures from standardized testing, there is little time dedicated to science in classrooms, as time is now devoted to reading and math (the tested subjects; Dillon, 2006; Jerald, 2006). A recent study found that kindergarten students receive an average of only 2.3 minutes of science instruction per day (Wright \& Neuman, 2014). Yet, outside of school, grown-ups and kids alike are spending significant time learning science in informal contexts such as zoos, aquariums, and museums. In fact, zoos in the United States have a higher annual attendance than all other cultural, sporting, and outdoor destinations combined (Schwan, Grajal, \& Lewalter, 2014).

We suggest that one way to reach the goals of public education, then, is to reimagine ways to bridge in-school experiences with out-of-school experiences that are attainable and meaningful to students in their everyday lives. Given that the zoo is a typical field trip encountered across the elementary grades and is one place from which students will likely learn outside of school, in this study, we examined how two kindergarten teachers designed a curricular unit that positioned scientific literacy as a set of interconnected, discipline-specific literacy practices and processes performed in relation to an authentic informational text.

\section{Scientific Literacy}

Over the last year, The Reading Teacher has been particularly attentive to the challenges of integrating science and literacy in the primary grades, exploring disciplinary talk (Wright \& Gotwals, 2017a), nonfiction writing (Kersten, 2017), and scientific inquiry (Clark \& Lott, 2017), to name only a few areas. Our work extends this conversation by examining the role of "authentic literacy activities" (Purcell-Gates, Duke, \& Martineau, 2007) with informational texts in bridging in-school and out-of-school science and literacy learning.

It is critical to consider the two distinct, dominant understandings of scientific literacy discussed across the literature (Pearson, Moje, \& Greenleaf, 2010): as knowledge of the natural world and as literacy practices, language, and textual forms that are intrinsically interconnected with the production of scientific knowledge. Whereas the former understanding positions scientific literacy as an outcome (i.e., the accumulation of facts), the latter, also promoted by the Next Generation Science Standards

Beth A. Buchholz is an assistant professor in the Department of Reading Education and Special Education at Appalachian State University, Boone, NC, USA; email buchholzba@appstate.edu

Damiana Gibbons Pyles is an associate professor in the Department of Curriculum and Instruction at Appalachian State University, Boone, NC, USA; email pylesdgaappstate.edu. 
(NGSS Lead States, 2013), positions scientific literacy as a range of practices and skills enacted in the process of doing, producing, and constructing scientific understanding. This view of scientific literacy fits well within a sociocultural perspective of literacy, which recognizes literacy as a set of social practices in which children engage throughout their lives and across home, work, religious settings such as church, and even in public spaces, such as the zoo (Barton \& Hamilton, 2000).

We argue that the latter view of scientific literacy, with a focus on practices and processes rather than the mere accumulation of facts, invites teachers to critically consider the authenticity of the informational texts used in the classroom and the purposes for reading or writing these texts as part of science activities and instruction. Aligned with PurcellGates and colleagues' (2007) work, we define authentic literacy activities as

PAUSE AND PONDER
How do you currently prepare
students to go on field trips?
What are some of your purposes and
goals for taking students on field
trips?
How do you support young students
in learning to read, use, and write
complex forms of genre-specific
texts?
What kinds of informational texts do
you use as part of your science
curriculum, and how might they be
used in more authentic ways?

At the center of this study were two teachers, Ms. $\mathrm{H}$ and Ms. S, and their combined classes of 28 students. Early on, the teachers began experimenting with co-teaching, bringing together their different strengths as educators to construct new curricular pathways and classroom structures. Ms. H self-identified as a "science person" and Ms. S as a "writing/literacy person," which opened up conversations about what it might look like to position literacy and science in meaningful, authentic ways in both in-school and out-ofschool contexts.

Rather than limit our analysis to the one-day field trip itself, we relied on our yearlong ethnographic work in these kindergarten classrooms to track how teachers carefully positioned the field trip as a connected and embodied experience within the formal curriculum. The data analyzed in this article are based on observational field notes record-

(a) reading and writing of textual types, or genres, that occur outside of a learning-to-read-and-write context and purpose [emphasis added], and (b) reading and writing those texts for the purposes for which they are read or written outside of a learning-to-read-and-write context and purpose [emphasis added]. (p. 14)

Importantly, these researchers found that providing young students with real-world reasons for engaging with authentic informational texts was the most significant factor in improving students' growth in their ability to read and write these genre-specific texts and, critically, that this method significantly outperformed the more traditional explicit explanation of genre function and features.

\section{Methods}

Our yearlong ethnographic study explored how two kindergarten teachers carefully positioned a field trip to the zoo as a connected and embodied experience within the formal kindergarten literacy curriculum. This study took place at Clearview Elementary School (all names are pseudonyms), a rural elementary school, during the 2016-2017 school year. The school is located in Dodd County, where approximately 52,000 residents live in the mountains of Appalachia. ed in the classroom, audiotapes of whole-class and small-group conversations, written student artifacts, and semistructured interviews with the classroom teachers.

\section{The Zoo Field Trip}

Zoos are the most popular out-of-school, informal context in which children and adults engage with and learn science content as well as develop their scientific literacy practices (Schwan et al., 2014). Although the insights shared as part of this research offer implications across a range of field trips, the zoo is a particularly powerful context in which to think through scientific literacy questions, given the significant role zoos play in the public's understanding of science.

To enhance the effectiveness of field trips, research and experience suggest that teachers should plan meaningful pre- and post-visit activities in the classroom (DeWitt \& Storksdieck, 2008). Given the earlier discussion of scientific literacy, in-class activities related to field trips must build content knowledge alongside particular ways of speaking, listening, reading, writing, viewing, and visually representing (i.e., the braided practices of the language arts curriculum; National Council of Teachers 
of English \& International Reading Association, 1996). Field trips such as the zoo offer students outof-school learning experiences where they are able to employ practices and processes learned in school.

The kindergarten field trip to the zoo in May was viewed by Ms. $\mathrm{H}$ and Ms. S as a critical element of teachers' yearlong curriculum map:

The plan all along from the beginning of the year was to build toward our zoo trip. So the zoo trip was the culmination of everything we've learned and putting it into real-life perspective, and so getting there and having all that knowledge and being able to not just experience the zoo but to relate it back to all the things that they've learned and to make those connections. (Ms. H)

The initial curricular steps in building toward the zoo began in early September. In terms of science content, the students and teachers moved from learning about bats (October) to black bears (January), brown bears (February), polar bears (March), and finally birds (April and May). These animals were selected based on opportunities to view them and their natural habitats at the zoo. Within each of these units, teachers thoughtfully incorporated opportunities for students to engage in reading a range of multimodally complex informational texts (books, magazines, diagrams, charts, and infographics), viewing photographs and videos, writing for a range of audiences and purposes (note-taking, $\mathrm{K}-\mathrm{W}-\mathrm{L}$ charts, journals, and prompts), visually representing scientific understandings on paper (illustrations and diagrams), speaking with peers and adults, and listening as ways of doing science (NGSS Lead States, 2013).

\section{Aviary Guide: An Authentic, Multimodal Informational Text}

Learning with multimodal texts involves creating meaning and producing texts in multiple ways (e.g., written text, images, sound, gesture) to create meaning socially between people and texts (Jewitt, 2008; Mavers, 2011). We specifically focus on one authentic, multimodal informational text and its use before, during, and after the field trip. The aviary guide, a one-page color bird identification guide, was authentic in that it was a "text that occur[ed] outside of a learning-to-read-and-write context and purpose" (Purcell-Gates et al., 2007, p. 14; see Figure 1). The guide is publicly available on the zoo's website and is used by people of all ages at the zoo (out of school) for the purpose of viewing the biological world in more detail (i.e., learning about and identifying birds). In addition to the printable, portable version available on the website, the aviary guide is also printed on large wooden exhibit placards inside the aviary itself (see Figure 2). The kindergarten teachers integrated a wide range of multimodal texts (Jewitt, 2008) across their zoo units, but the aviary guide was unique in that teachers recognized the benefits of having a text that students could literally hold in their hands at the zoo and a text that they could write on.

The aviary guide was a multimodal informational text that helped the students create meaning in multiple ways, which was essential because

science inherently requires the use of these multiple sign systems, scientific literacy accordingly involves the comprehension of multimodal texts, or texts that convey meaning through multiple sign systems, such as gestures, spoken words, written words, numeric equations, photographs, diagrams, and so forth. Therefore, literacy instruction in science classrooms must prepare students to understand, critically evaluate, and design these multimodal texts. (Wilson, 2008, p. 154)

Working with and learning from multiple texts in science (or any content area) is not always intuitive as students must be taught how to engage with and learn from texts with different features and characteristics, such as various images, different vocabulary, and different designs or arrangements. In the classrooms in our study, the teachers not only spent a significant amount of time teaching students how to engage with multimodal texts but also teaching them to produce multimodal writings and drawings to represent their emerging scientific knowledge.

\section{Into the Classroom and Off to the Zoo: Literacy and Science Sensemaking "Each in the Service of the Other"}

In this section, we examine teachers' key curricular decisions related to the aviary guide before, during, and after the field trip to the zoo. In addition, we analyze students' experiences across these events as emerging readers, writers, and scientists. In an effort to highlight how literacy and science sensemaking practices were positioned "each in the service of the other" (Pearson et al., 2010, p. 459), we organize the analyses according to the six core English language arts practices: reading, viewing, listening, speaking, writing, and visually representing. Although we highlight particular practices as occurring before, 
Figure 1

The Aviary Guide

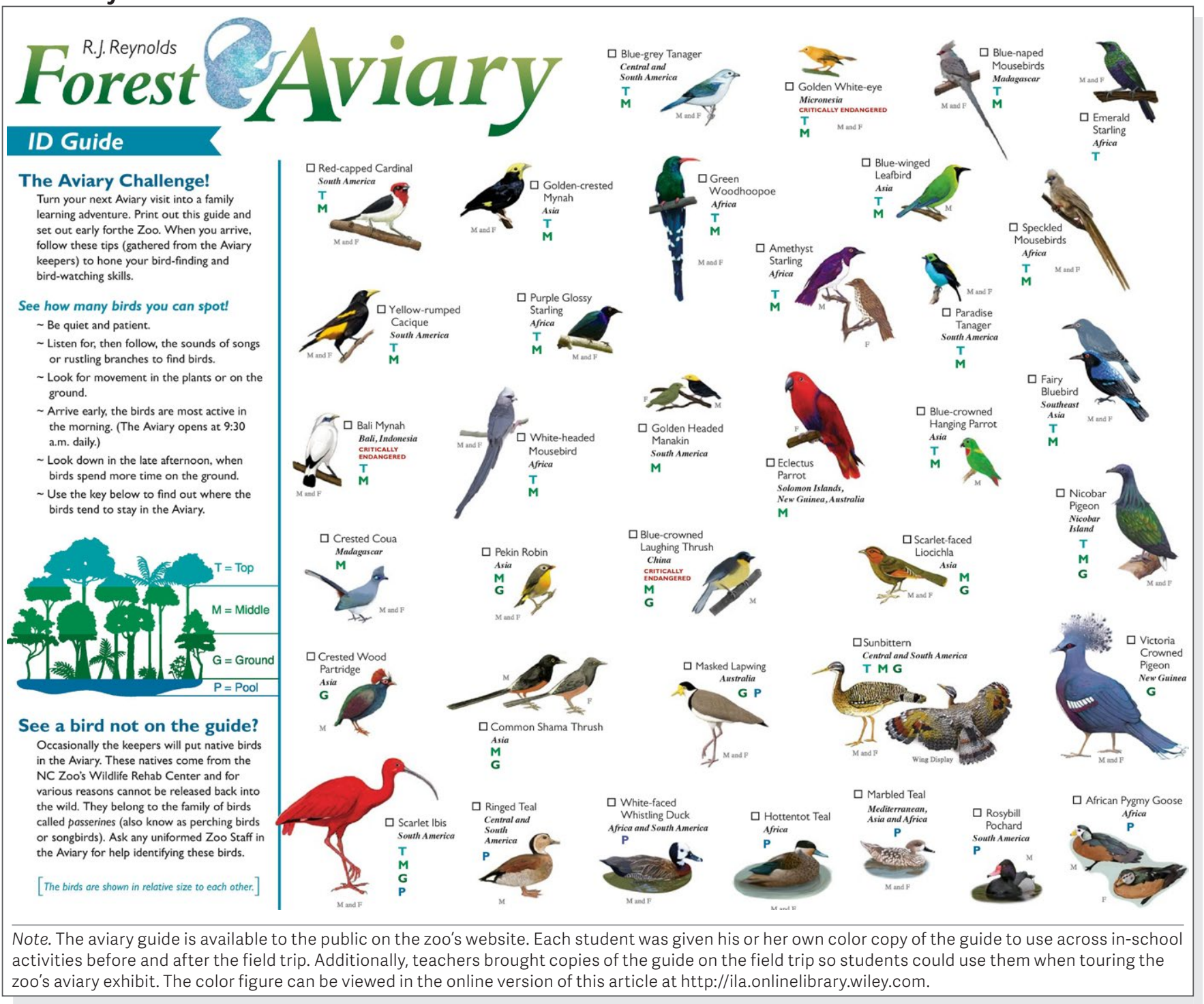

during, or after the field trip, this is simply a strategy for organizing our findings; we urge readers to keep in mind that the practices were intertwined and entangled across the school-based temporal boundaries.

\section{Before the Zoo: Reading and Viewing Multimodal Texts}

In the final weeks leading up to the zoo field trip, students and teachers transitioned from their study of bears into an inquiry into birds. To mark this turning point, each student received his or her own color copy of the aviary guide (see Figure 1).
To begin with we talked about going to the aviary, and I pulled out the [aviary] guide [saying] these are some of the birds that are going to be in the aviary. Of course, they don't really know what an aviary is at that point in time, so we have to talk about a vocabulary word right there. (Ms. H)

Having used the aviary guide with young students for many years, Ms. $\mathrm{H}$ had a clear vision for how to help her early and emergent kindergarten readers make sense of this complex multimodal text with a range of text features. The Next Generation Science Standards expect that students in grades $\mathrm{K}-2$ learn to obtain information using various text features 


\section{Figure 2}

\section{A Placard With Information on Birds and Plants in the Zoo's Aviary}

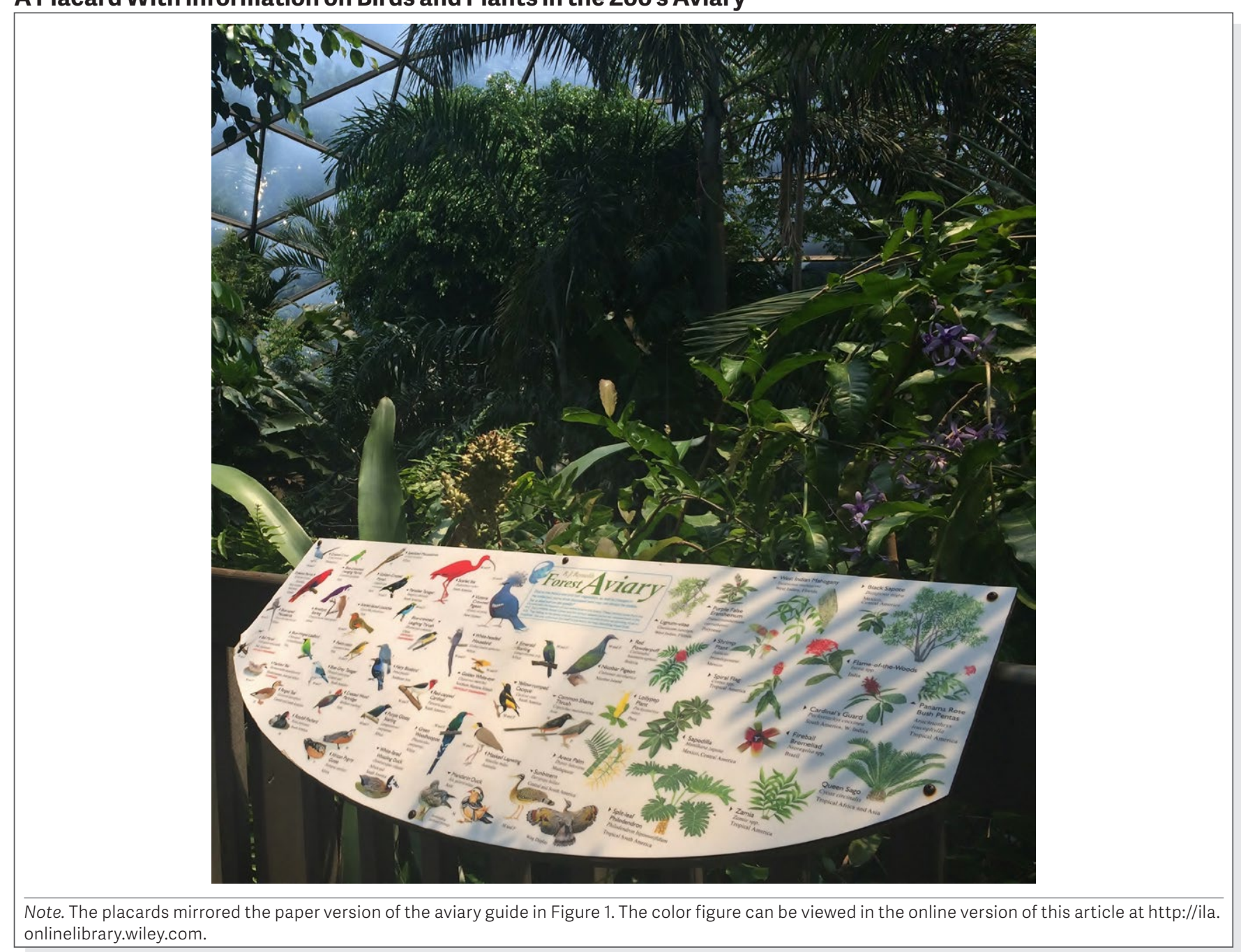

"that will be useful in answering a scientific question and/or supporting a scientific claim" (NGSS Lead States, 2013, p. 6). In this case, the aviary guide was a particularly rich source of text features for these early and emergent readers (e.g., headings, bold font, italicized font, colored font, diagram, color-coded initials; see Figures 1 and 3). Interestingly, Ms. $\mathrm{H}$ was intentional about not beginning with explicit modeling (Pearson \& Gallagher, 1983; Purcell-Gates et al., 2007); instead, students were given repeated opportunities and extended time to explore and use the guide in the classroom for authentic purposes and contexts aside from learning to read.

As a result, these young readers discovered text features and structures and asked questions about different parts of the guide, which Ms. H leveraged for in-the-moment whole-group teaching moments and lessons. For example, students were quick to pick up on text features such as the bird drawings, names (large font label), and geographic location (italicized label), but it took longer for questions to emerge related to the aviary diagram/key and color-coded initials for aviary locations (see Figure 3).

I kind of let them discover this part [diagram/key] so there's discovery in that, so someone will eventually say, "Hey, what does that mean over here?" And then we'll have a group discussion, and we'll pull it up [on the document camera] and we'll say, "What do you think this means?" And then the children end up making the connection...between the colors and then they realize what they mean. (Ms. H) 


\section{Figure 3}

Some Key Elements or Features Found on the Aviary Guide

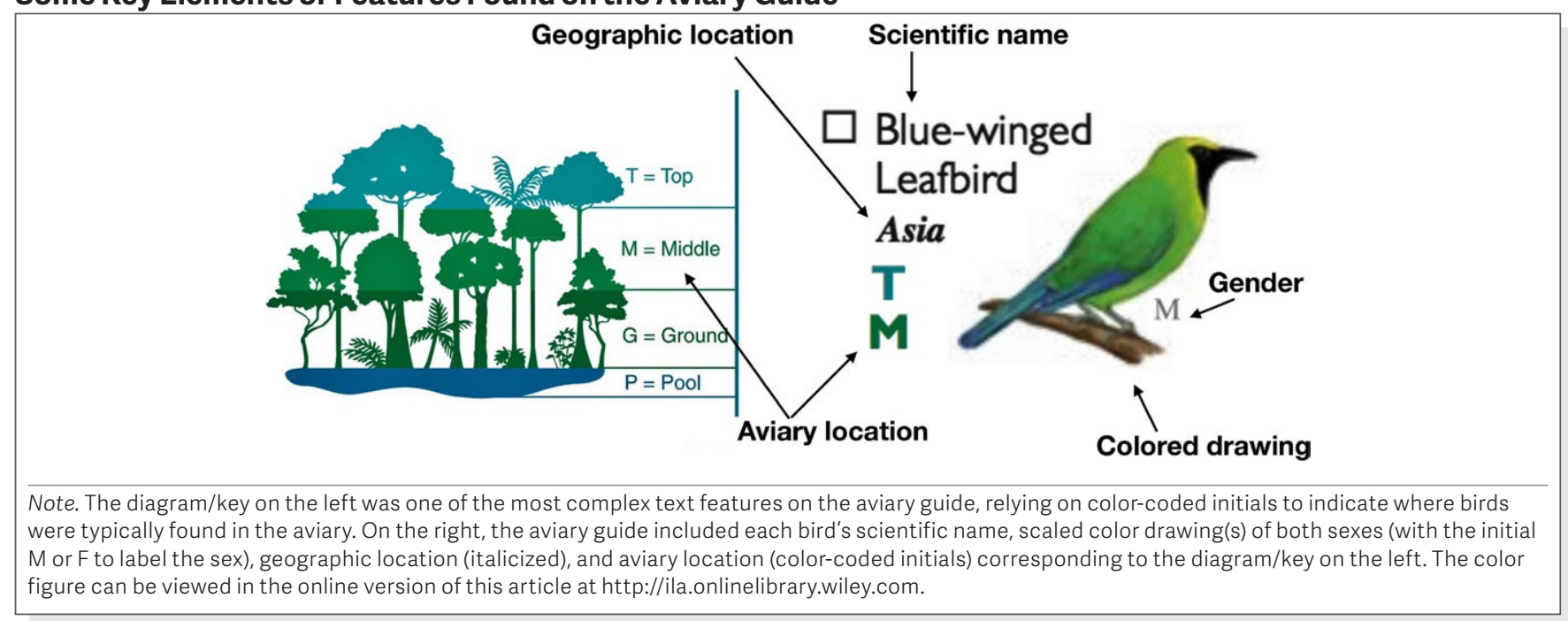

It was evident in students' subsequent talk (in school and at the zoo) and writing that this explicit discussion of the aviary diagram and the color-coded initials was particularly influential for these young readers and scientists. It was this connected set of text features that offered students an alternative process of identification in the aviary. In this way, extended and repeated use of the multimodal text in school led to more explicit instruction and discussions around how to use it and how to learn from it.

During the bird unit, a typical whole-class science lesson would focus on a particular kind of bird that students were likely see in the aviary. Using a range of nonfiction texts (e.g., video, photographs, diagrams, maps, posters), teachers supported students in learning about the bird's physical characteristics and typical behaviors. As part of this lesson, or a set of lessons, students were always invited to locate the bird on their aviary guide, with teachers offering repeated opportunities for guided practice with reading and viewing the guide (e.g., skimming words and drawings to locate a particular bird). Using talk and gestural movements, the kindergartners collaboratively supported one another in learning to use the guide quickly and efficiently. In whole- and smallgroup contexts, students practiced locating a bird based on its name and/or image and used the guide to visually connect and organize new learning.

Alongside this focus on learning about different kinds of birds and linking this learning to the aviary guide, teachers also led a series of lessons focused on comparing particular physical characteristics across different kinds of birds (e.g., beak size and shape, foot shape, body shape). Because the aviary guide used birds drawn to relative scale, it was especially useful in inviting students to engage in the scientific and mathematical practices and related discourses of comparison. In other words, it was not enough for students to know what all birds have in common (e.g., feathers, wings, two feet); the inschool experiences with the aviary guide pushed students to see what made birds different from one another and to learn how to talk about these differences (e.g., shorter, longer, wider, sharper).

By incorporating the aviary guide across various in-school contexts for a full month before going on the zoo field trip, teachers offered students multiple and varied experiences in reading and viewing an authentic, multimodal informational text and using it as part of learning to engage in the discourse of science (Wright \& Gotwals, 2017a, 2017b). Even though the aviary guide was introduced and initially used in a school context, we argue that teachers invited students to use the guide in fairly authentic ways and for authentic purposes that mirrored scientific literacy practices necessary for the out-ofschool field trip experience (e.g., viewing/observing, reading, identifying, comparing, talking).

\section{At the Zoo: Embodied Experiences With Multimodal Text-in-Use}

When planning a zoo trip, teachers are faced with the challenge of how to support the development of scien- 
tific literacy during a field trip in authentic, meaningful ways that are more than school-based add-ons to an out-of-school experience. The question becomes, What kinds of texts-and interrelated reading, writing, speaking, listening, viewing, and representing practices-might any zoo-goer of any age engage in as part of an out-of-school experience at the zoo? For the teachers at the center of this study, the aviary guide became the tool that invited young students to engage with a text during the trip as a way of doing science and producing scientific knowledge.

Reading and Viewing as Embodied Experiences. One strategy the students relied on was using text features from the aviary guide to help them find the birds at the zoo. Once a bird was spotted in the environment, students paid particular attention to where it was located rather than what it looked like (at least initially). Using this firsthand observational data, students scanned the guide for the corresponding initial or color that indicated where each bird tended to stay in the aviary (see Figure 3). In this way, students narrowed down the possibilities before looking carefully at a bird's physical characteristics to identify it. Here, students demonstrated their understanding of the guide as a particular kind of informational text with related text features and structures that could be used to support viewing (and the production of knowledge). It is critical to point out that students' extensive use of the guide during pre-visit activities was essential in supporting their productive use of the guide-and related practices-during the trip, ultimately allowing students to view the birds in the aviary differently than the casual zoo visitor.

DisciplinarySpeaking and ListeningasSocial Practices. As part of this integrated enactment of reading and viewing in the aviary, these young students were also involved in producing public knowledge through the complex social practices of speaking and listening in relation to a text (the guide). Students' experiences on this zoo field trip-and in the aviary in particularwere highly social. Whereas during family-based zoo trips, the social context commonly involves adults interpreting and explaining the exhibits to children, during the zoo field trip, it was the kindergartners who were collaboratively sharing and constructing science knowledge with one another.

Ms. S: And just walking into the aviary, and the students] were teaching. They were the leaders. They were the teachers. They were spotting the animals. They were talking about it.
Ms. H: They were going up to other people in the aviary and pointing things out.

Ms. S: Yes! That's right, “That's a scarlet ibis!”...and talking about their beaks, and you know they had their guide and they had their crayon.

It is noteworthy that the use of the guide in the aviary was not constructed as an individual assignment or assessment but rather as a chance for the joint construction and production of knowledge through the enactment of speaking and listening intertwined with reading and viewing in a real-world context. Specifically, in using the guide in the aviary, kindergartners gained practice engaging in disciplinary talk for science: using evidence to support one's claims (National Research Council, 2012; Wright \& Gotwals, 2017b). For example, upon observing a bird in the aviary, students would read or scan the guide and say or enact a version of "I think it's a [state the name of the bird and/or point to the bird on the guide] because [specific observations of physical characteristics and/or location]." These claims were not always taken up by peers but could be openly debated by citing additional evidence either garnered from observing other details of the bird itself or from the image of the bird on the guide.

\section{After the Zoo: Writing and Visually Representing}

Writing about one's experience is an extremely common activity in elementary school classrooms after a field trip. Writing is perhaps one of the most obvious ways that sensemaking processes in science are always intertwined with literacy practices. Scientists must be able to communicate their findings to colleagues as well as the public. The Next Generation Science Standards expect students in grades $\mathrm{K}-2$ to "communicate information...in written forms using models, drawings, writing, or numbers that provide detail about scientific ideas" (NGSS Lead States, 2013, p. 15). A process approach to writing instruction parallels many of the same practices and processes expected of scientists (e.g., posing a question/ making a claim, doing research, drafting a position, conferring with others, revising, publishing results).

Although many forms of writing and purposes for writing occurred in the weeks before and after the field trip, here we highlight a single writing invitation that focused on kindergartners producing 
informational writing and visual representations. Despite decades of research to the contrary (e.g., Donovan \& Smolkin, 2006; Pappas, 1993; Tower, 2003), many teachers are still reluctant to incorporate informational or explanatory writing in the curriculum based on assumptions that "children's abilities to understand and compose stories precede their capabilities to understand and use non-story, informational written language" (Pappas, 1993, p. 97). Informational texts continue to be far less common in primary classroom reading and writing instructional contexts than are narrative stories (Duke, 2000; Moss, 2008).

Based on these widespread, long-standing beliefs and assumptions, it is logical that kindergarten teachers such as Ms. $\mathrm{H}$ and Ms. S, under pressure to provide evidence of students' literacy growth, would use narrative prompts on formal end-of-year writing assessments. So, when Ms. H decided to take a risk and steer away from another narrative prompt, she did so with some fear about how good the students' writing would be. Despite this fear, with students' yearlong experiences with informational texts, classroom discussions, and animal inquiries, as well as embodied and enacted experiences with an authentic text on the zoo field trip, Ms. H felt that students were primed to do some writing as scientists rather than storytellers. She explained to students that the final "on-your-own writing" of the year was to write about a bird on the aviary guide that they had learned about this year, but in the midst of explaining the prompt, Landry's question "threw [her] for a loop": "Excuse me. Do we have to write about a bird that we've already learned about, or we can we just pick a bird that we haven't learned about?"

Informational writing in school is often constructed upon an understanding of scientific literacy as the acquisition and representation of knowledge (Pearson et al., 2010), but Landry's seemingly simple question offered an alternative version for how and why scientists use the practices of writing and representing in the real world.

And my first gut was to tell [Landry] no. It really was, and I thought, Well, wait, we're being scientists, and so...let's see what you can figure out. I actually kind of wanted to see. But I mean, really and truly, my first instinct was to say, "You've got to do [a bird] we've already done," and I thought, Well, that's not what a scientist would do. (Ms. H)

Subsequently, Ms. H extemporaneously revised the prompt:
You can write about a bird that you've already learned about on the aviary guide. Or, you may choose a different bird from the [aviary] guide that we haven't talked about and be a scientist: describe the physical characteristics of that bird and then make some predictions about what you think it might eat or where it might live or what kind of bird it is that we could find out about later.

Essentially, this tweak invited students to write from a place of curiosity built upon the extensive background knowledge, embodied practices, and scientific literacy practices developed across the year. During the writing time, students had their aviary guides out on their desks and used the text to support their production of written text as well as detailed visual representations of birds.

In the end, teachers were pleasantly surprised that all students-with guided reading levels ranging from pre-A to G-produced on-topic visual representations and written text independently on this end-of-year kindergarten writing assessment. (See Figure 4 for a sample of Landry's end-of-year writing, which reflected his use of the aviary guide as a scientific resource for writing about and visually representing information accurately.) Not a single student expressed reluctance or resistance to informational writing during this on-demand assessment.

We argue that a critical element of students' success was teachers' pedagogical decision to allow for the use of the aviary guide (and related experiences with it, both in and out of school) as an interactive part of the process of informational or explanatory writing and visual representation. Rather than viewing the use of textual resources negatively as a form of cheating or copying, these teachers understood reading the room as a highly appropriate strategy for supporting the production of alphabetic text in kindergarten and beyond. Students interacted with multimodal aspects of the aviary guide to produce alphabetic text about a bird's name, physical characteristics (closely viewing the illustrations), geographic location, endangered status, and location in the aviary or a forest. Using the aviary guide as a writing tool required far more than simplistic copying skills (Mavers, 2011). Students had to understand how to read or view the guide to get information (formulated in words and phrases) and then turn these bits of information into complete sentences or thoughts, requiring disciplinary content knowledge (academic vocabulary) and discipline-specific literacy practices (syntax and discourse). 


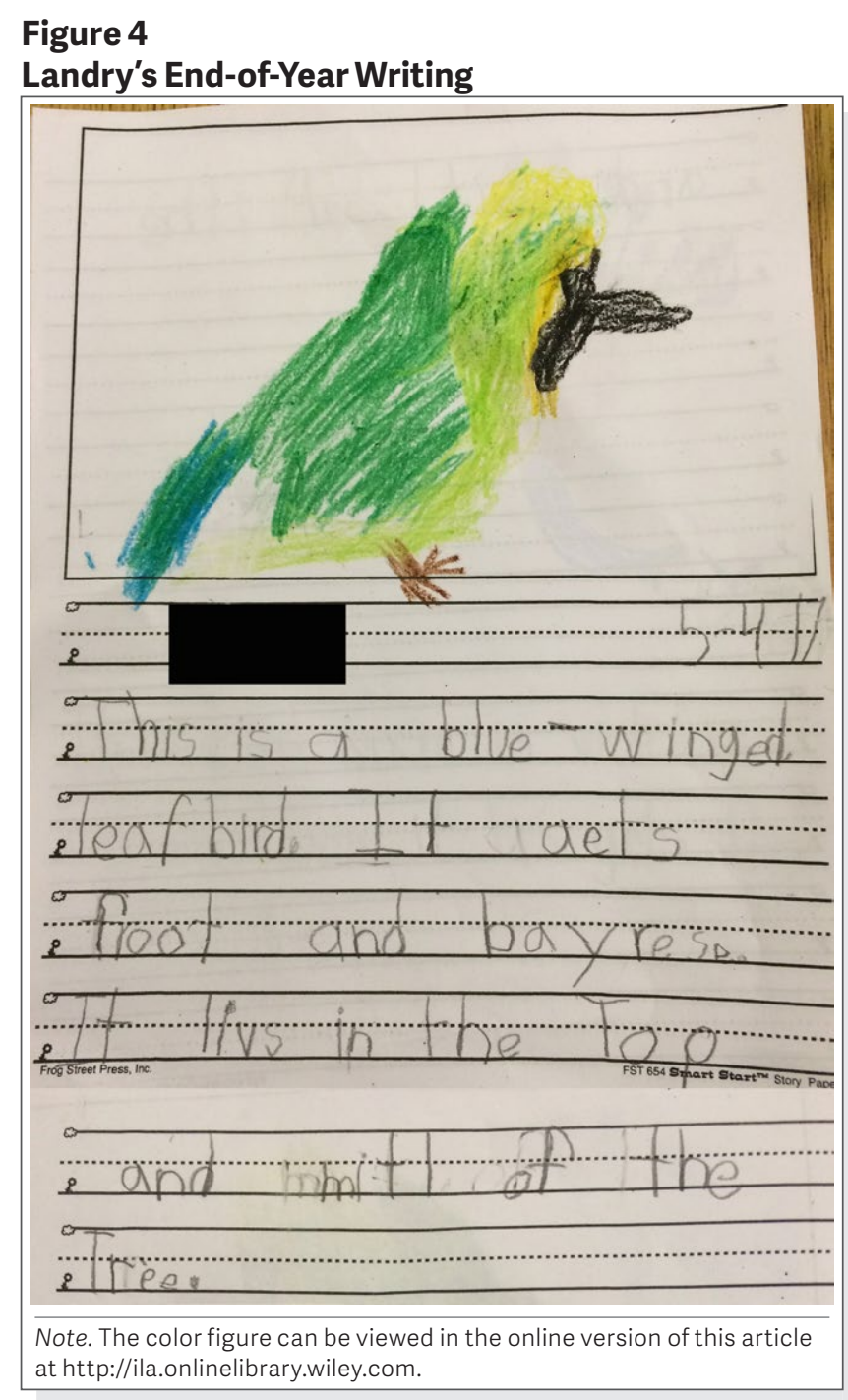

\section{Significance and Conclusion}

Certainly, field trips to informal science contexts promote students' engagement in and knowledge of science content, but, critically, there are opportunities to do more than promote the accumulation of knowledge. Our work with Ms. H and Ms. S suggests that teachers can support students' development of strong scientific literacy through rich literacy practices intertwined with learning science content, over a length of time, with multiple, varied, and scaffolded uses of an authentic, multimodal text, and when paired with an authentic, out-of-school learning experience. Ultimately, the aviary guide served as a critical tool of students' enacted, embodied practices in the aviary, helping students frame the real world scientifically by naming the world using contentspecific vocabulary.
Importantly, it was the ways of and purposes for using the aviary guide in school that mattered; it was not enough to simply use this authentic, multimodal text in service of traditional literacy goals (e.g., memorizing names of birds [sight words], reading and rereading names of birds from left to right and top to bottom [directionality and reading fluency], copying the birds' names [writing]). Over the years, Ms. $\mathrm{H}$ found that the authentic sensemaking practices developed in school around the aviary guide transformed how her kindergartners experienced the zoo:

And [the students] would have stayed [in the aviary]. They would have stayed longer. They were very excited about it.... We were in there a long time. In fact, we blocked the walkway the whole time we were in there.... and people couldn't get around us, literally. I kept having to move us to the side because [the students] were looking at all the birds.

The aviary, once seen as a hot, uninteresting exhibit that students and teachers would rush through in hopes of moving on to more exciting exhibits, became one of the most highly anticipated parts of the trip. Students spent more than 40 minutes there, aviary guides and crayons in hand, patiently scanning the enclosed habitat for a chance to spot the much studied birds.

\section{TAKE ACTION!}

1. Explore complex multimodal texts that a visitor might use at this location to support their experience (e.g., maps, brochures, cell phone, websites, signage, tablet). Websites for museums and zoos offer a wealth of resources for both formal and informal trips.

2. When selecting texts, ensure that each text has an authentic purpose outside of school that real people would use and represents multiple modes of representation (e.g., alphabetic text, visual/graphic, mathematical, audio). Texts in the real world include everything from newspapers to signs to YouTube videos.

3. Plan your pretrip curriculum so students are invited to interact with the texts multiple times, in varied ways, across a range of social contexts.

4. Look for authentic opportunities for students to engage in reading and writing during the field trip connected to the multimodal texts used in school.

5. After the field trip, consider how authentic textsused before and during the field trip-could be used as tools for informational or explanatory writing that parallel the practices and processes of scientists (see NGSS Lead States, 2013). 
Following the lead of Ms. $\mathrm{H}$ and Ms. S, we recommend that teachers across all grade levels should consider what and how multimodal informational texts are used by typical visitors in different field trip spaces - an aviary guide at the zoo, a guidebook at the history museum, an interactive app at the aquarium, a plant identification pamphlet at the nature center, or a map at the apple orchard. Field trips promote students' engagement in and knowledge of the content areas, but, critically, field trips are also rich opportunities for students to enact discipline-specific literacy practices for authentic purposes. Thoughtfully selected authentic, multimodal informational texts used before, during, and after a field trip offer all students an embodied understanding of how reading, viewing, talking, listening, writing and visually representing can be used to learn about the world beyond the classroom window.

\section{REFERENCES}

Barton, D., \& Hamilton, M. (2000). Literacy practices. In D. Hamilton, M. Hamilton, \& R. Ivanič (Eds.), Situated literacies: Reading and writing in context (pp. 7-15). New York, NY: Routledge.

Clark, S.K., \& Lott, K. (2017). Integrating science inquiry and literacy instruction for young children. The Reading Teacher, 70(6), 701-710. https://doi.org/10.1002/trtr.1572

DeWitt, J., \& Storksdieck, M. (2008). A short review of school field trips: Key findings from the past and implications for the future. Visitor Studies, 11(2), 181-197. https://doi. org/10.1080/10645570802355562

Dillon, S. (2006, March 26). Schools cut back subjects to push reading and math. The New York Times, p. 1.

Donovan, C.A., \& Smolkin, L.B. (2006). Children's understanding of genre and writing development. In C.A. MacArthur, S. Graham, \& J. Fitzgerald (Eds.), Handbook of writing research (pp. 131-143). New York, NY: Guilford.

Duke, N.K. (2000). 3.6 minutes per day: The scarcity of informational texts in first grade. Reading Research Quarterly, 35(2), 202-224. https://doi.org/10.1598/RRQ.35.2.1

Jerald, C.D. (2006). The hidden costs of curriculum narrowing [Issue brief]. Washington, DC: The Center for Comprehensive School Reform and Improvement.

Jewitt, C. (2008). Multimodality and literacy in school classrooms. Review of Research in Education, 32(1), 241-267.

Kersten, S. (2017). Becoming nonfiction authors: Engaging in science inquiry. The Reading Teacher, 71(1), 33-41. https://doi. org/10.1002/trtr.1577

Mavers, D. (2011). Children's drawing and writing: The remarkable in the unremarkable. New York, NY: Routledge.

Moss, B. (2008). The information text gap: The mismatch between non-narrative text types in basal readers and 2009 NAEP recommended guidelines. Journal of Literacy Research, 40(2), 201-219. https://doi.org/10.1080/10862960802411927

National Council of Teachers of English \& International Reading Association. (1996). Standards for the English language arts. Urbana, IL: National Council of Teachers of English; Newark, DE: International Reading Association.

National Research Council. (2012). A framework for K-12 science education: Practices, crosscutting concepts, and core ideas. Washington, DC: National Academies Press.

NGSS Lead States. (2013). Next Generation Science Standards: For states, by states. Washington, DC: National Academies Press.
Pappas, C.C. (1993). Is narrative "primary"? Some insights from kindergarteners' pretend readings of stories and information books. Journal of Reading Behavior, 25(1), 97-129. https://doi.org/10.1080/10862969309547803

Pearson, P.D., \& Gallagher, G. (1983). The gradual release of responsibility model of instruction. Contemporary Educational Psychology, 8(3), 112-123.

Pearson, P.D., Moje, E., \& Greenleaf, C. (2010). Literacy and science: Each in the service of the other. Science, 328(5977), 459-463. https://doi.org/10.1126/science.1182595

Purcell-Gates, V., Duke, N.K., \& Martineau, J.A. (2007). Learning to read and write genre-specific text: Roles of authentic experience and explicit teaching. Reading Research Quarterly, 42(1), 8-45. https://doi.org/10.1598/RRQ.42.1.1

Schwan, S., Grajal, A., \& Lewalter, D. (2014). Understanding and engagement in places of science experience: Science museums, science centers, zoos, and aquariums. Educational Psychologist, 49(2), 70-85. https://doi.org/10.1080/00461520. 2014.917588

Tower, C. (2003). Genre development and elementary students' informational writing: A review of the literature. Literacy Research and Instruction, 42(4), 14-39.

Wilson, A.A. (2008). Moving beyond the page in content area literacy: Comprehension instruction for multimodal texts in science. The Reading Teacher, 62(2), 153-156. https://doi. org/10.1598/RT.62.2.7

Wright, T.S., \& Gotwals, A.W. (2017a). Supporting disciplinary talk from the start of school: Teaching students to think and talk like scientists. The Reading Teacher, 71(2), 189-197. https://doi.org/10.1002/trtr.1602

Wright, T.S., \& Gotwals, A.W. (2017b). Supporting kindergartners' science talk in the context of an integrated science and disciplinary literacy curriculum. The Elementary School Journal, 117(3), 513-537. https://doi.org/10.1086/690273

Wright, T.S., \& Neuman, S.B. (2014). Paucity and disparity in kindergarten oral vocabulary instruction. Journal of Literacy Research, 46(3), 330-357. https://doi.org/10.1177/108629 6 X14551474

\section{MORE TO EXPLORE}

- Kirchen, D.J. (2011). Making and taking virtual field trips in pre-K and the primary grades. Young Children, 66(6), 22-26.

- Mayger, L. (2007). Making the most of field trips. Educational Leadership, 64(9). Retrieved from http://www. ascd.org/publications/educational-leadership/summer07/ vol64/num09/Making-the-Most-of-Field-Trips.aspx

- Varelas, M., \& Pappas, C.C. (Eds.). (2013). Children's ways with science and literacy: Integrated multimodal enactments in urban elementary classrooms. New York, NY: Routledge.

- "For Educators," resources by the Smithsonian: https://www.si.edu/educators

- "Integrating Literacy Strategies Into Science Instruction," a series of professional development workshops by the American Museum of Natural History: https://www.amnh.org/explore/curriculum-collections/ integrating-literacy-strategies-into-science-instruction 